\title{
Letter to the Editor: Is Older Age a Contraindication for Single-Level Transforaminal Lumbar Interbody Fusion?
}

\author{
Vishal Kumar, Sarvdeep Singh Dhatt, Vijay G. Goni, Akshat Srivastava \\ Department of Orthopaedics, Postgraduate Institute of Medical Education and Research, Chandigarh, India
}

Dear Editor,

We have read the article "Is older age a contraindication for single-level transforaminal lumbar interbody fusion?" by Patel et al. [1] with great interest and appreciate the authors for their informative work. This article was extensively discussed in our departmental journal club meeting recently and few doubts were raised which seek solution and redressal before establishing safety and utility of transforaminal lumbar interbody fusion (TLIF) amongst the elderly. In this study, the authors have tried to address the doubts regarding the utility of TLIF amongst the elderly by comparing their outcome to a younger population. They have taken Wang and Bohlman's criteria for functional outcome apart from Visual Analog Scale and Oswestry Disability Index. Firstly, as we understand, any surgery when performed in the elderly population is not only subjected to local complications but also to systemic complications. This becomes significant in the elderly who often have multiple comorbidities which pose a higher risk to operative intervention [2]. In this study authors have mentioned comorbidities in quantitative terms (single versus more than two comorbidities); however, no qualitative analysis in terms of type and severity of comorbidities has been performed.
Secondly, the authors have not taken other coexisting causes of low backache into consideration including osteoporosis [3], which might affect the long-term outcome, especially when comparing to a younger population. We look forward to acknowledging these doubts before coming to a definitive conclusion.

\section{Conflict of Interest}

No potential conflict of interest relevant to this article was reported.

\section{References}

1. Patel JY, Kundnani VG, Chawada B. Is older age a contraindication for single-level transforaminal lumbar interbody fusion? Asian Spine J 2021;15:447-54.

2. Schoenfeld AJ, Carey PA, Cleveland AW 3rd, Bader JO, Bono CM. Patient factors, comorbidities, and surgical characteristics that increase mortality and complication risk after spinal arthrodesis: a prognostic study based on 5,887 patients. Spine J 2013;13:11719.

3. Borenstein DG. Chronic low back pain. Rheum Dis Clin North Am 1996;22:439-56.

Received Oct 5, 2021; Accepted Oct 17, 2021

Corresponding author: Akshat Srivastava

Department of Orthopaedics, Postgraduate Institute of Medical Education and Research, Madhya Marg, Sector 12 Chandigarh, 160012, India

Tel: +91-7978378521, E-mail: akshatofficial@gmail.com 